\title{
Evaluation of a Substitute Structure Method to Estimate Seismic Displacement Demand in Piers and Wharves
}

\author{
Rakesh K. Goel, ${ }^{\text {a) }}$ M.EERI
}

This paper compares seismic displacement from the MOTEMS and the ASCE/COPRI 61-14 substitute structure method (SSM) with results from the nonlinear response history analysis (NLRHA). It is found that the SSM is biased toward overpredicting displacement demand for short-period systems and underpredicting displacement demand for long-period systems. The overprediction was found to be excessive for very-short period systems (i.e., systems with periods shorter than the period at which the design spectrum transitions from linearly increasing spectral acceleration to constant spectral acceleration). It is recommended that the SSM not be used for such systems. It is also recommended that the SSM not be used for long-period systems (i.e., systems with periods longer than the period at which the design spectrum transitions from constant spectral acceleration to constant spectral velocity), where it underpredicts displacement demand and may lead to unconservative design. The SSM provides reasonable results (within $20 \%$ of results from NLRHA) for systems with periods in the constant spectral acceleration region of the design spectrum. [DOI: 10.1193/030917EQS045M]

\section{INTRODUCTION}

The substitute structure method (SSM) was originally proposed in the mid-1970s by Gulkan and Sozen (1974) and Shibata and Sozen (1976) as a design (not an analysis) procedure to determine design forces corresponding to a given type and intensity of earthquake motion represented by the design spectrum (Shibata and Sozen 1976). The specific objective was to establish minimum strengths of structure components so that a tolerable response displacement would likely not be exceeded. With recognition of the importance of displacements, this method received renewed attention in the early 1990s for displacement-based design (Calvi and Kingsley 1994, Kowalski et al. 1994a and 1994b). Subsequently, Priestley et al. (1996) proposed several versions of the SSM for displacement-based design of bridges. More recently, Sozen (2003) advocated for consideration of drift (or displacement) response in earthquake-resistant design and provided an efficient method to estimate drift.

These SSMs involve replacing the inelastic system with a substitute linear-elastic system with an effective stiffness and an effective damping, while keeping the mass constant, with the expectation that displacement of the original nonlinear system will be the same as that of the substitute linear-elastic system. The substitute structure will generally have a period

\footnotetext{
a) Associate Dean and Professor of Civil and Environmental Engineering, College of Engineering, California Polytechnic State University, San Luis Obispo, CA 93407
} 


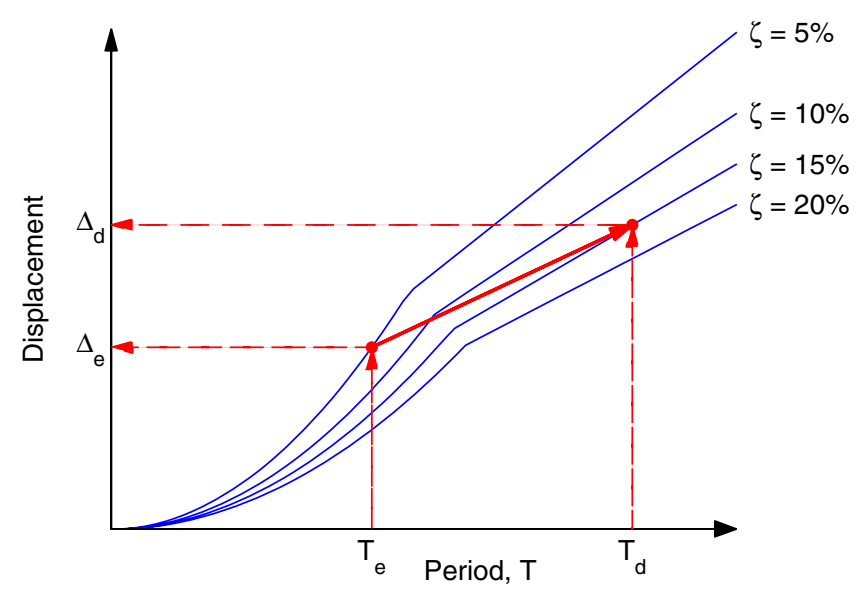

Figure 1. Period elongation and increased damping in the SSM (adapted from Goel and Goel 2017).

longer than, and a damping higher than, that the period and damping of the initial elastic structure (Figure 1). In most cases, period elongation leads to larger displacement and higher damping leads to lower displacement.

When originally developed, the SSM was evaluated against results from nonlinear response history analysis (NLRHA) for two ground motions (see Table 1). Based on these results, Gulkan and Sozen (1974) found that $\mu$ 's exact and approximate vales agreed well. This observation seems to indicate that the SSM provides demands that are sufficiently close to those from the NLRHA. However, Gulkan and Sozen (1974) were primarily concerned with estimating design base shear rather than displacement demand. Table 1 summarizes the differences in ductility demand between the SSM and the NLRHA. These results show several instances where the SSM is close to from the NLRHA, with differences less than $10 \%$. However, the difference is very large, $+60-50 \%$, in several other cases, indicating either significant over- or underestimation.

Other SSM variations, such as the nonlinear static procedure (NSP) in ATC-40 and FEMA-273 (ATC 1996, FEMA 1997) or the capacity spectrum method (Freeman et al. 1975, Freeman 1978), have been proposed. These methods share with the SSM the basic concept of an elongated period and increased equivalent damping, as shown in Figure 1, to represent a nonlinear system with an equivalent linear-elastic system. However, the procedure to compute equivalent damping varies among these methods.

The NSP in ATC-40 and FEMA-273 was evaluated in a study by Chopra and Goel (2000). It was found that it may significantly over- or underestimate deformation, with errors approaching 50\%. Hutchinson et al. (2002) also evaluated these methods for extended pile shaft-supported bridge structures and found that the SSM overestimated demands by about $40 \%$. These studies indicate that the SSM may not always provide reasonable estimates of seismic displacement demand. 
Table 1. Comparison of calculated ductility ratio from NLRHA and SSM (adapted from Gulkan and Sozen 1974)

\begin{tabular}{|c|c|c|c|c|c|c|c|}
\hline \multirow[b]{3}{*}{$\begin{array}{l}\text { Initial } \\
\text { Period (s) }\end{array}$} & \multirow[b]{3}{*}{$\begin{array}{l}\text { Base shear } \\
\text { coefficient }\end{array}$} & \multicolumn{6}{|c|}{ Value of ductility ratio, $\mu$} \\
\hline & & \multicolumn{3}{|c|}{ El Centro, 1940, N } & \multicolumn{3}{|c|}{ Managua 1972, E } \\
\hline & & NLRHA & SSM & $\begin{array}{c}\text { Difference } \\
(\%)\end{array}$ & NLRHA & SSM & $\begin{array}{c}\text { Difference } \\
(\%)\end{array}$ \\
\hline \multirow[t]{3}{*}{0.15} & 0.16 & 28.5 & 26 & -9.6 & 28.8 & 26 & -10.8 \\
\hline & 0.32 & 4.1 & 10 & 60.0 & 13.0 & 10 & -30.0 \\
\hline & 0.48 & 3.3 & 5 & 34.0 & 5.2 & 6 & 13.3 \\
\hline \multirow[t]{3}{*}{0.50} & 0.16 & 8.0 & 6 & -33.3 & 5.6 & 6 & 6.7 \\
\hline & 0.32 & 2.9 & 3 & 3.3 & 2.8 & 3 & 6.7 \\
\hline & 0.48 & 2.0 & 2 & 0.0 & 2.0 & 2 & 0.0 \\
\hline \multirow[t]{3}{*}{1.0} & 0.08 & 4.9 & 6 & 18.3 & 5.6 & 6 & 6.7 \\
\hline & 0.16 & 2.5 & 2 & -25.0 & 3.0 & 2 & -50.0 \\
\hline & 0.24 & 1.5 & 1.5 & 0.0 & 1.3 & 1.5 & 13.3 \\
\hline \multirow[t]{3}{*}{2.0} & 0.04 & 4.6 & 5 & 8.0 & 4.5 & 4 & -12.5 \\
\hline & 0.08 & 2.0 & 3 & 33.3 & 1.9 & 2 & 5.5 \\
\hline & 0.12 & 1.5 & 2 & 25.0 & 1.4 & 2 & 30.0 \\
\hline
\end{tabular}

The SSM has been adopted in MOTEMS (CSLC 2016) and in ASCE/COPRI 61-14 (ASCE 2014) for estimating seismic demands in piers and wharves. In MOTEMS it is based on the procedure presented in Priestley et al. (1996, sec. 5.3.1(c)) while in ASCE/ COPRI 61-14 it is based on a slightly different version from Priestley et al. (1996, sec. 4.5.2(b) (iii)). Both methods share SSM general characteristics: elongation of period and increased damping. However, MOTEMS restricts the SSM to systems with a period less than $T_{o}$, which is defined as a period where constant acceleration and constant velocity regions of the design spectrum intersect; the displacement demand in the nonlinear system is taken as that of the initial elastic system for periods longer that $T_{o}$. ASCE/COPRI 61-14 does not restrict SSM in this way.

A study by Goel and Goel (2017) examined the convergence behavior of the MOTEMS and ASCE/COPRI 61-14 methods. It was found that the MOTEMS method does not converge when the first estimate of the displacement demand is taken as that of the initial linearelastic, 5\%-damped system. It may converge if the initial estimate is sufficiently close to the final solution. When it converges, the MOTEMS method leads to a displacement demand similar to that from the ASCE/COPRI 61-14 method, which Goel and Goel found to converge consistently. The researchers recommended that the ASCE/COPRI 61-14 method be used in lieu of the MOTEMS method for structures that are designed according to MOTEMS requirements.

Practicing engineers prefer the SSM, as is apparent from its adoption in MOTEMS (CSLC 2016), ASCE/COPRI 61-14 (ASCE 2014), ATC-40 (ATC 1996), and FEMA-273 (1997). The SSM is simple to implement and can be used with design spectra. 
While implementation of the NLRHA is somewhat straightforward, it still requires significantly more computational effort: selection of spectrum-compatible ground motions, implementation of the NLRHA for each ground motion, and statistical analysis of results to obtain design value.

However, the ability of the SSM, when compared with the NLRHA, to predict peak seismic displacement demand has been questioned (e.g., Chopra and Goel 2000, Hutchinson et al. 2002). When developed initially, the SSM was meant to obtain only first-order estimates of seismic demand; it was never intended to provide high-level accuracy in seismic displacement calculation. Yet it was adopted in MOTEMS (CSLC 2016) and ASCE/COPRI 61-14 (ASCE 2014) to make decisions about the acceptability of seismic designs of piers and wharves.

It is clear from the discussion so far that there is a need to re-examine the ability of the MOTEMS and ASCE/COPRI 61-14 SSMs to estimate seismic displacement demands in marine oil terminals and other piers and wharves. This investigation is aimed at filling this need. For this purpose, seismic displacement demands from the SSM are compared against those obtained from the NLRHA using two sets of ground motions. The first set consists of 20 ground motions from the SAC study (Somerville et al. 1997), and the second set consists of 80 ground motions from the NGA-West 2 database (PEER 2013). Since results from the MOTEMS SSM, when convergence was achieved, were found to be the same as those from ASCE/COPRI 61-14 (Goel and Goel 2017), only the ASCE/COPRI 61-14 SSM is considered here.

\section{ASCE/COPRI 61-14 SSM}

Following is a summary of the SSM in ASCE/COPRI 61-14 standard:

1. Idealize the pushover curve from nonlinear pushover analysis (Figure 2) and estimate the yield force, $F_{y}$, and yield displacement, $\Delta_{y}$.

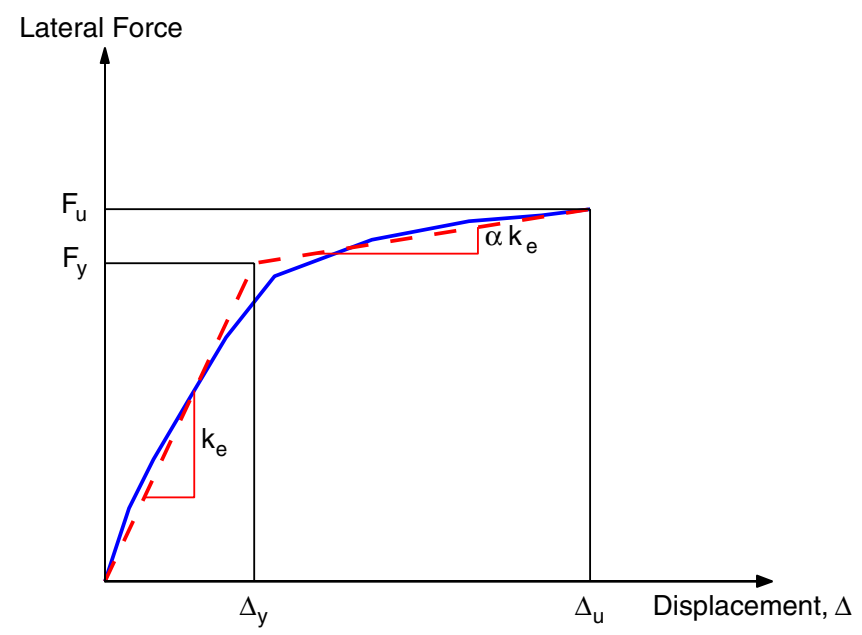

Figure 2. Idealization of nonlinear pushover curve (adapted from Goel and Goel 2017). 
2. Compute the effective linear-elastic lateral stiffness, $k_{e}$, as the yield force, $F_{y}$, divided by the yield displacement, $\Delta_{y}$.

3. Compute the effective linear-elastic structural period in the direction under consideration from

$$
T_{e}=2 \pi \sqrt{\frac{m}{k_{e}}}
$$

4. Determine the displacement, $\Delta_{d}$, of the effective linear-elastic system from

$$
\Delta_{d}=S_{A} \frac{T_{e}^{2}}{4 \pi^{2}}
$$

where $S_{A}$ is the $5 \%$-damped spectral acceleration corresponding to the linear-elastic structural period, $T_{e}$.

5. Select the initial estimate of the displacement demand in the SSM as

$$
\Delta_{d, i}=\Delta_{d}
$$

6. Compute the ductility, $\mu_{\Delta, i}$ :

$$
\mu_{\Delta, i}=\frac{\Delta_{d, i}}{\Delta_{y}}
$$

7. Use the appropriate relationship between ductility and damping for the component undergoing inelastic deformation to estimate the effective structural damping, $\xi_{\text {eff,i }}$. In lieu of more detailed analysis, use the following relationship for concrete and steel piles connected to the deck through dowels embedded in the concrete:

$$
\xi_{e f f, i}=0.05+\frac{1}{\pi} \quad 1 \quad \frac{1}{\sqrt{\mu_{\Delta, i}}} \quad \alpha \sqrt{\mu_{\Delta, i}}
$$

where $\alpha$ is ratio of post-yield stiffness to initial elastic stiffness (see Figure 2).

8. Compute the force, $F_{d, i}$, on the force-deformation relationship associated with the estimated displacement, $\Delta_{d, i}$ (Figure 3).

9. Compute the effective stiffness, $k_{e f f, i}$, as the secant stiffness from

$$
k_{e f f, i}=\frac{F_{d, i}}{\Delta_{d, i}}
$$

10. Compute the effective period, $T_{e f f, i}$, from

$$
T_{e f f, i}=2 \pi \sqrt{\frac{m}{k_{e f f, i}}}
$$

11. For the effective structural period, $T_{e f f, i}$, and the effective structural damping, $\xi_{e f f, i}$, compute the spectral acceleration $S_{A}\left(T_{e f f, i} \xi_{e f f, i}\right)$ from an appropriately damped design acceleration response spectrum. 


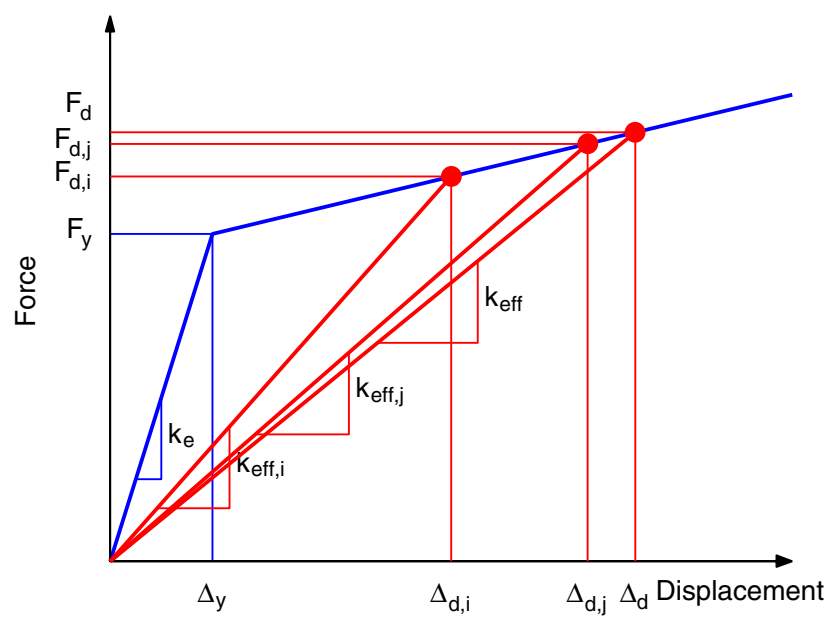

Figure 3. Solution strategy and effective stiffness in the SSM (adapted from Goel and Goel 2017).

12. Compute the new estimate of the displacement, $\Delta_{d, j}$, from:

$$
\Delta_{d, j}=\frac{T_{e f f, i}^{2}}{4 \pi^{2}} S_{A} T_{e f f, i}, \zeta_{e f f, i}
$$

13. Repeat steps 6-12 with $\Delta_{d, i}=\Delta_{d, j}$ until the displacement, $\Delta_{d, j}$, computed in Step 12 is sufficiently close to the starting displacement, $\Delta_{d, i}$, in Step 6 (Figure 3).

The effective damping in the ASCE/COPRI 61-14 SSM (Equation 5) is based on Kowalsky et al. (1994a), which used the Takeda material hysteresis model (Takeda et al. 1970) (Figure 4). The effective damping in the substitute structure is equal to sum of the $5 \%$ damping in the initial elastic system and the equivalent damping dissipated due to system nonlinearity. Using the procedure described in Chopra (2017), the equivalent damping due to system nonlinearity is given by

$$
\zeta_{e q}=\frac{1}{4 \pi} \frac{E_{D}}{E_{S o}}
$$

in which $E_{D}$ is the area under the force-deformation curve under cyclic loading, with the frequency of the forcing function equal to the natural vibration frequency of the system, and $E_{S o}$ is the strain energy given by

$$
E_{S o}=\frac{1}{2} F_{u} \Delta_{u}
$$

Kowalski et al. (1994a) proposed computing $E_{D}$ as the area under the loop after several cycles at the same maximum deformation, which is shown as the shaded area in Figure 4 and is given by

$$
E_{D}=F_{u}\left(2 \Delta_{u} \quad 2 \Delta_{o}\right)
$$




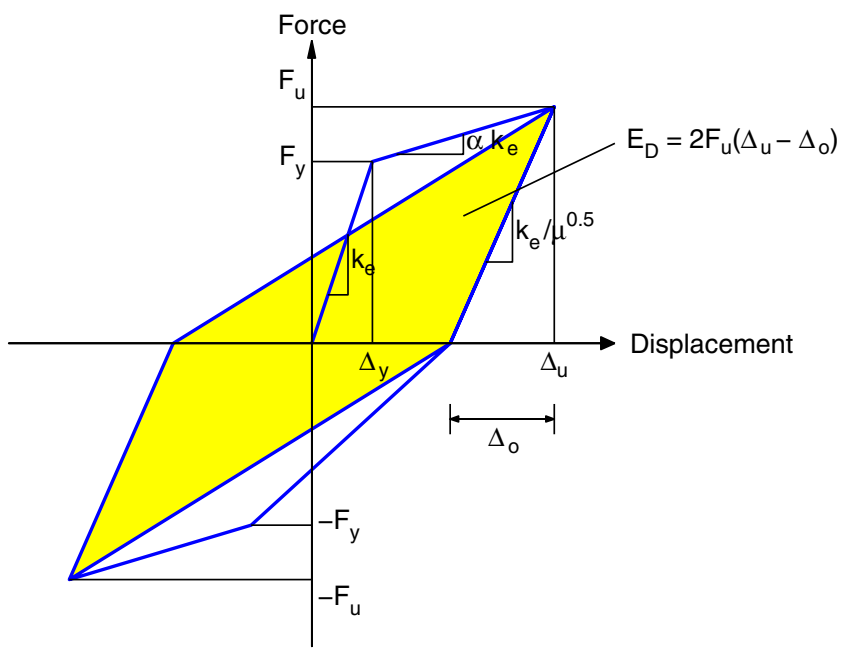

Figure 4. Takeda force-deformation model (taken from Takeda et al. 1970) and estimation of equivalent damping ratio in the SSM.

where

$$
\Delta_{o}=\frac{F_{u}}{k_{e} / \sqrt{\mu}}
$$

Using Equations 10-12 in Equation 9 leads to

$$
\begin{aligned}
& \zeta_{\text {eq }}=\frac{1}{4 \pi} \frac{2 F_{u} \quad \Delta_{u} \quad \frac{F_{u}}{k_{e} / \sqrt{\mu}}}{(1 / 2) F_{u} \Delta_{u}}=\frac{1}{\pi} \frac{1}{\Delta_{u}} \Delta_{u} \quad \frac{k_{e} \Delta_{y}+\alpha k_{e}\left(\Delta_{u} \quad \Delta_{y}\right)}{k_{e}} \sqrt{\mu} \\
& =\frac{1}{\pi} 1 \frac{\Delta_{y}+\alpha\left(\Delta_{u} \quad \Delta_{y}\right)}{\Delta_{u}} \sqrt{\mu}=\frac{1}{\pi} 1 \quad \frac{\Delta_{y} \quad \alpha \Delta_{y}+\alpha \Delta_{u}}{\Delta_{u}} \sqrt{\mu} \\
& =\frac{1}{\pi} 1 \quad \alpha+\frac{1 \quad \alpha}{\mu} \sqrt{\mu}=\frac{1}{\pi} 1 \quad \frac{1}{\sqrt{\mu}} \quad \alpha \sqrt{\mu}
\end{aligned}
$$

Adding the $5 \%$ damping of the initial elastic system to $\zeta_{e q}$ in Equation 13 leads to

$$
\zeta_{\text {eff }}=0.05+\frac{1}{\pi} 1 \quad \frac{1 \quad \alpha}{\sqrt{\mu}} \quad \alpha \sqrt{\mu}
$$

which is the effective damping in Equation 5. 


\section{EVALUATION APPROACH}

The SSM is evaluated by examining the ratio

$$
\Delta=\frac{\Delta_{S S M}}{\Delta_{N L R H A}}
$$

where $\Delta_{S S M}$ and $\Delta_{N L R H A}$ are the peak displacement demands of single-degree-of-freedom (SDF) system from the SSM and NLRHA, respectively. To assess the effects of system nonlinearity level, $R_{y}=2,4,8$, and 10 were considered, where $R_{y}$ is defined as the ratio of the system strength required for the system to remain linear-elastic and the yield strength. System nonlinearity is characterized by a bilinear force-deformation relationship with $5 \%$ post-yield stiffness.

The NLRHA of the SDF system is implemented in OpenSees (McKenna and Fenves 2011) using the Takeda hysteresis material model. It is important that the force-deformation relationship used in the NLRHA be consistent with that used in the SSM to compute effective damping. To verify this consistency, Figure 5 shows the force-deformation of a selected nonlinear SDF system, confirming that the force-deformation response using the OpenSees material model is consistent with that assumed in the ASCE/COPRI 61-41 SSM to estimate effective damping (Figure 4).

The ASCE/COPRI 61-14 SSM, described in the preceding section, is implemented in MATLAB (MathWorks 2014). In this implementation, peak displacement demands in Steps 2-9 are computed from analysis of the system's linear response history with appropriate vibration period and damping; the original method in ASCE/COPRI 61-14 estimates these demands from a design spectrum.

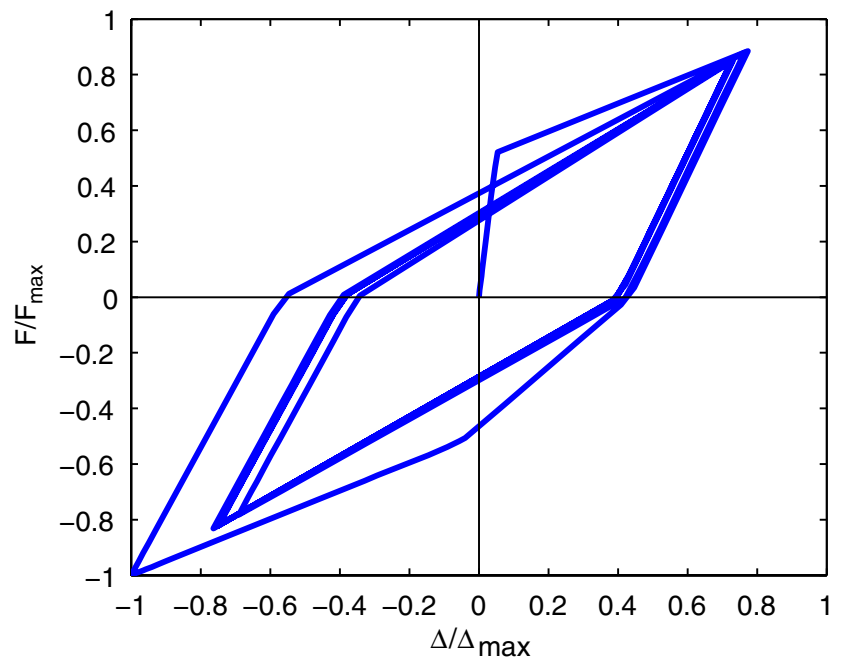

Figure 5. Force-deformation behavior of the material used in OpenSees for the NLRHA. 
A procedure is biased if the median of the ratio $\Delta$ differs from 1; it is biased toward underestimating response if the ratio is less than 1 and toward overestimating response if the ratio exceeds 1 . Thus, the SSM is evaluated in this paper by investigating the median of the ratio for peak displacement demand. The median is computed as the geometric mean of the ratio:

$$
\hat{\Delta}=\exp \sum_{i=1}^{n} \ln \left(\Delta_{i}\right) / n
$$

\section{SELECTED GROUND MOTIONS}

Two sets of ground motions are used in this investigation. The first set, consisting of 20 ground motions, is designated the SAC ground motion set; it was developed by the SAC study for $10 \%$ probability of exceedance in 50 years for a site in Los Angeles, California (Somerville et al. 1997). The second set, consisting of 80 ground motions, is designated the NGA-West2 ground motion set and contains ground motions, selected from the NGA-West2 database (PEER 2013), that are compatible with the site-specific spectrum in MOTEMS for Level 2 (or 10\% probability of exceedance in 50 years) for the Port of Long Beach, California. The elastic response spectra for individual ground motions and medians for each set are shown in Figure 6.

\section{EVALUATION OF THE ASCE/COPRI 61-14 SSM}

The results in Figures 7 and 8 indicate that the SSM may either overpredict or underpredict peak displacement demand for an individual ground motion, as apparent from the ratio $\Delta$ being much higher or lower than 1 . However, the SSM is systematically biased toward overprediction for systems with short periods and underprediction for systems with long periods. This is apparent from the median of $\Delta$ being larger than 1 for systems with short periods and smaller than 1 for systems with long periods.

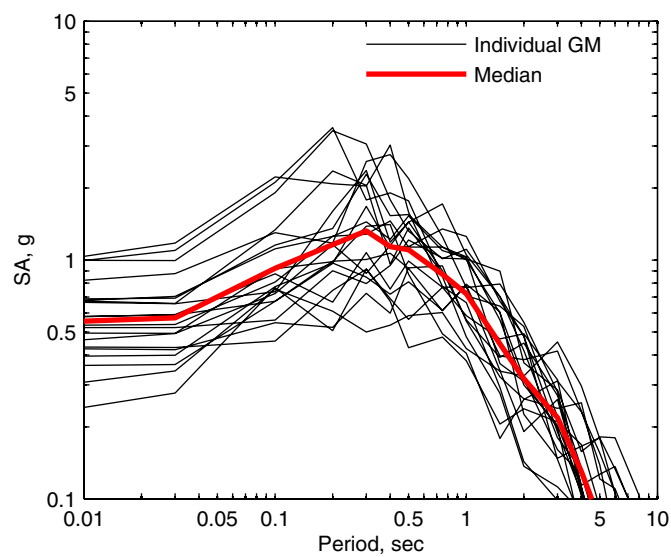

(a)

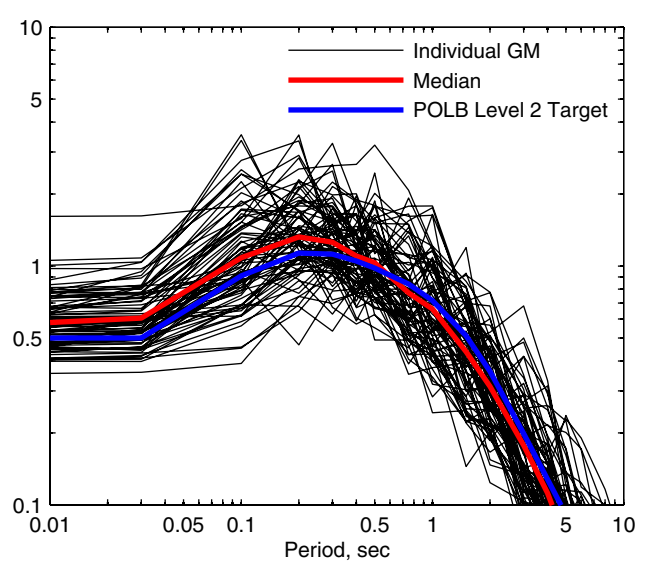

(b)

Figure 6. Response spectrum for (a) SAC ground motions and (b) NGA-West2 ground motions. 


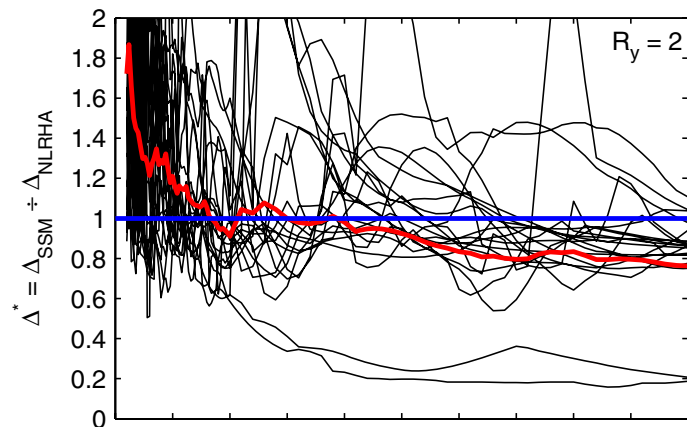

(a)

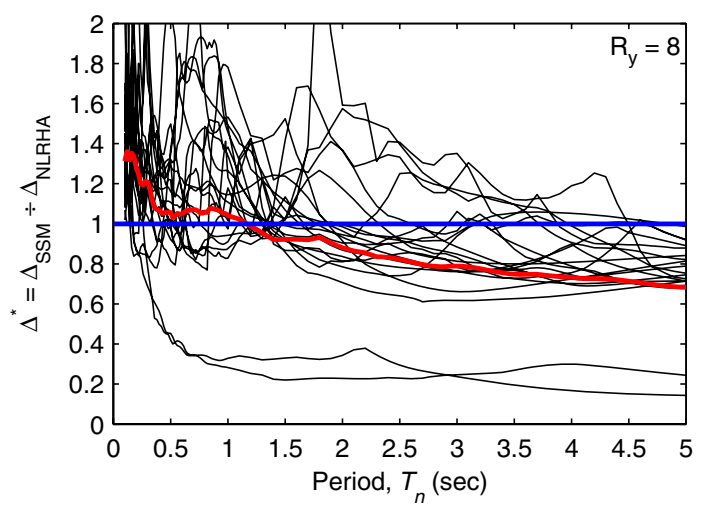

(c)

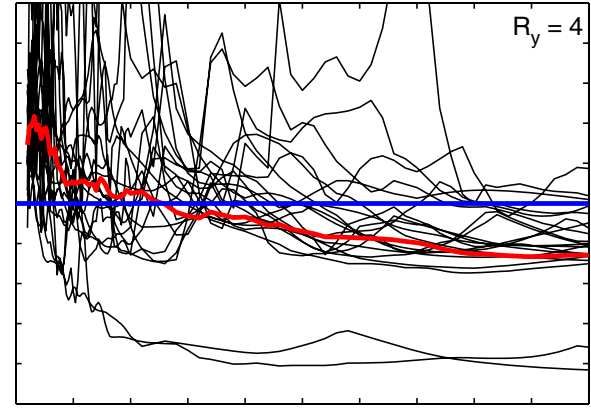

(b)

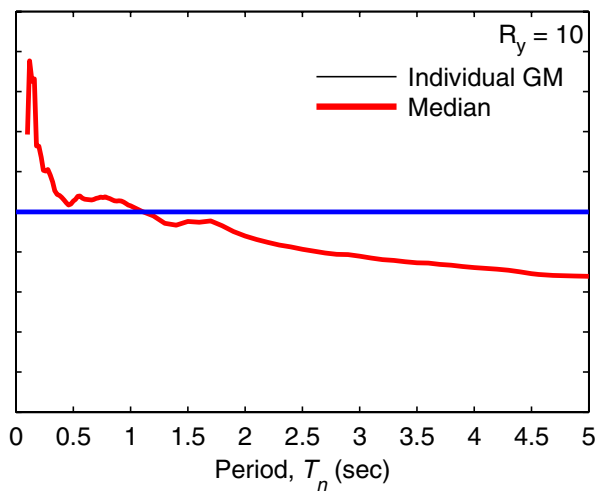

(d)

Figure 7. Ratio of peak displacement demand from the SSM and the NLRHA for SAC ground motions.

The bias in the SSM toward overpredicting displacement demand tends to be very large for very-short-period systems, in many cases exceeding 50\% (Figures $7 \mathrm{a}, 7 \mathrm{~d}, 8 \mathrm{c}$, and 8d). As shown in Appendix A, the significant overprediction for very-short-period system occurs because of implicit assumptions in the SSM. Recall that effective period and damping in the SSM are computed at peak displacement demand. Since not all cycles of vibration occur at this deformation, the SSM errs on the side of longer periods and higher damping. Also recall that period elongation generally has the effect of increasing displacement and higher damping has the effect of reducing it. For very-short-period systems, displacement is insensitive to damping and thus higher damping does not greatly affect displacement demand. However, displacement is highly sensitive to error in period elongation for very-short-period systems and the tendency of the SSM to err on the side of longer periods leads to significant displacement demand overprediction. The very-short-period region is defined as the region between the zero period and the period where the design spectrum transitions from the linearly increasing spectral acceleration region to the constant spectral acceleration region. For example, periods in this region are less than $0.3 \mathrm{~s}$ for the SAC median spectrum.

For systems with periods in the constant spectral region, the SSM overpredicts displacement demand but by no more than $20 \%$. Therefore, it is expected to provide reasonable 


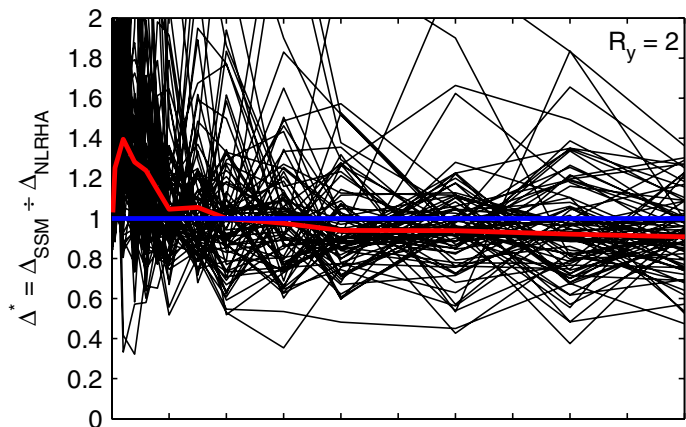

(a)

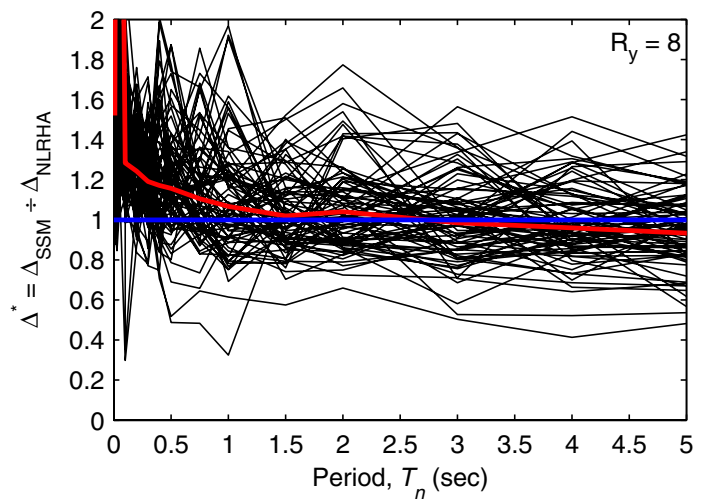

(c)

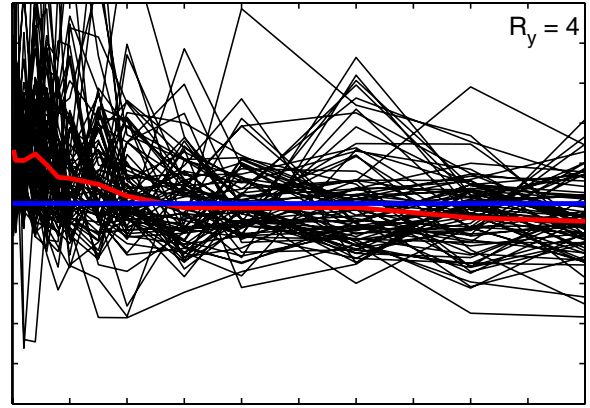

(b)

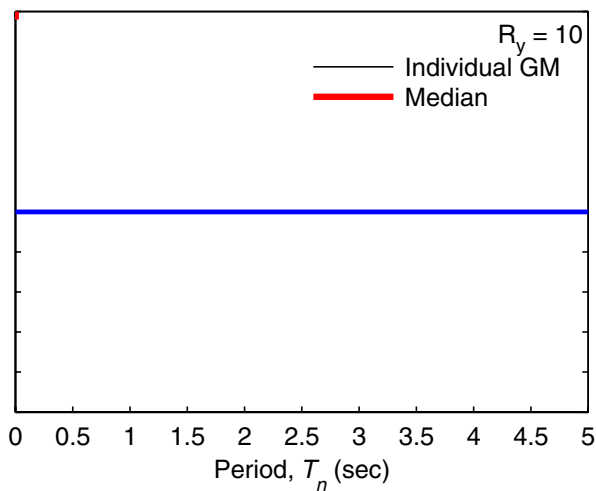

(d)

Figure 8. Ratio of peak displacement demand from the SSM and the NLRHA for NGAWest2 ground motions.

results, although perhaps with some overprediction, in the constant spectral region. For the SAC median spectrum, this region is between 0.3 and $1 \mathrm{~s}$.

The SSM tends to underpredict displacement demand for longer-period systems that fall in the velocity- and displacement-sensitive regions (i.e., beyond the constant spectral acceleration region). For such systems, displacement of the nonlinear system should be approximately equal to that of the linear-elastic system irrespective of nonlinearity level. In these regions, system response is sensitive to damping. The tendency of the SSM to err on the side of higher damping leads to lower displacement and thus underprediction of displacement demand. Periods longer than $1 \mathrm{~s}$ fall in these regions for the SAC median spectrum.

The underprediction of displacement demand by the SSM for systems in the period range beyond the constant spectral acceleration region may lead to unconservative design. Therefore, it may not be appropriate to use the SSM to estimate displacement demand for longer-period systems. MOTEMS precludes use of the SSM beyond the constant spectral acceleration region, but ASCE/COPRI 61-14 does not. Therefore, it is recommended that ASCE/COPRI 61-41 also preclude use of the SSM beyond the constant spectral acceleration region; the displacement demand of nonlinear systems with periods longer than those beyond 
the constant spectral acceleration region may simply be estimated as that of corresponding linear-elastic systems.

These observations are consistent, in general, for different values of $R_{y}$ for systems beyond the very-short-period region. However, overprediction by the SSM for systems with periods in the very-short-period region, in some cases, may increase with increasing values of $R_{y}$ (Figures $7 \mathrm{~d}, 8 \mathrm{c}$, and $8 \mathrm{~d}$ ). Moreover, these observations are generally consistent for both the SAC (Figure 7) and the NGA-West2 (Figure 8) ground motion set, indicating that the conclusions from this study may be applicable to other characterizations of ground-shaking hazards. Slight differences occur for longer-period systems where the SSM may underpredict displacement demand by as much as $25 \%$ for the SAC ground motions (Figure 7), but the underprediction is slightly smaller for the NGA-West2 ground motions (Figure 8).

The discussion so far indicates that the SSM should not be used to estimate displacement demand for very-short-period systems because it significantly overpredicts displacement, in many cases by more $50 \%$. Nor should it be used for longer-period systems because it underpredicts displacement demand and thus may lead to unconservative design. On the other hand, it can be used for systems that fall in the constant spectral acceleration region where it provides reasonable results (within $20 \%$ of the NLRHA value).

\section{CONCLUSIONS AND RECOMMENDATIONS}

This investigation on adequacy of MOTEMS and ASCE/COPRI 61-14 SSMs leads to the following conclusions:

- $\quad$ The SSM is biased toward overpredicting the displacement demands of short-period systems (i.e., systems with periods shorter than the period at which the design spectrum transitions from linearly increasing spectral acceleration to constant spectral acceleration. It is biased toward underpredicting the displacement demands of longer-period systems (i.e., systems with periods longer than the period at which the design spectrum transitions from constant spectral acceleration to constant spectral velocity).

- $\quad$ SSM overprediction for very-short-period systems may be excessive, resulting in displacement estimates, in the median, that exceed NLRHA values by more than $50 \%$.

- $\quad$ The SSM provides reasonable results only in the constant spectral acceleration region of the earthquake design spectrum.

- These observations are found to be mostly consistent for two different sets of ground motions and different levels of system inelastic behavior; however, overprediction for very-short-period systems may become excessive for systems with lower yield strength (or larger $R_{y}$ values).

Based on these conclusions, the following recommendations are provided for use of the ASCE/COPRI 61-14 and MOTEMS SSMs:

- $\quad$ This method should not be used for systems with very short periods because it will overpredict displacement demand possibly by more than $50 \%$. 
- This method should not be used for systems with periods beyond the constant acceleration region of the earthquake design spectrum because it will underpredict displacement demand, leading to unconservative design.

- This method may be used for systems in the constant acceleration region of the earthquake design spectrum. Engineers should be aware that the SSM may overpredict displacement demand by $20 \%$ for such systems.

\section{ACKNOWLEDGMENTS}

The early part of this research was supported by the California State Lands Commission (CSLC) under Contract No. C2013-054. This support is gratefully acknowledged.

\section{APPENDIX}

Please refer to the online version of this paper to access the supplementary material provided in the Appendix.

\section{REFERENCES}

ASCE (American Society of Civil Engineers), 2010. minimum design loads for buildings and other structures. ASCE/SEI 7-10, Reston, VA.

ASCE (American Society of Civil Engineers), 2014. Seismic design of piers and wharves. ASCE/ COPRI 61-14, Reston, VA.

ATC (Applied Technology Council), 1996. Seismic Evaluation and Retrofit of Concrete Buildings, Report ATC-40, Redwood City, CA.

CSLC (California State Lands Commission), 2016. Marine Oil Terminal Engineering and Maintenance Standards (MOTEMS), Title 24, California Code of Regulations, Part 2, Sacramento

Calvi, M. C., and Kingsley, G. R., 1994. Displacement based seismic design of multi-degree-offreedom bridge structures. In Proceedings of the 2nd International Workshop on the Seismic Design of Bridges, 8-13 August, Queenstown, New Zealand,.

Chopra, A. K., 2017. Dynamics of Structures: Theory and Applications to Earthquake Engineering, 5th ed., Pearson, Hoboken, NJ.

Chopra, A. K., and Goel, R. K., 2000. Evaluation of a NSP to estimate seismic deformation: SDF systems, Journal of Structural Engineering 126(4), 482-490.

CSLC (California State Lands Commission), 2016. Marine Oil Terminal Engineering and Maintenance Standards (MOTEMS), Title 24, California Code of Regulations, Part 2, California Building Code, Chapter $31 F$ (Marine Oil Terminals), Sacramento.

FEMA (Federal Emergency Management Agency), 1997. NEHRP Guidelines for the Seismic Rehabilitation of Buildings, Report No. FEMA-273, Washington, D.C.

Freeman, S. A., 1978. Prediction of Response of Concrete Buildings to Severe Earthquake Motion, Publication SP-55, American Concrete Institute, Detroit, 589-605.

Freeman, S. A., Nicoletti, J. P., and Tyrell, J. V., 1975. Evaluations of existing buildings for seismic risk-A case study of Puget Sound Naval Shipyard, Bremerton, Washington. In Proceedings of the 1st U.S. National Conference on Earthquake Engineering, Earthquake Engineering Research Institute (EERI), Berkeley, CA, 113-122. 
Goel, R., and Goel, H., 2017. Convergence behavior of substitute structure method in MOTEMS. In Proceedings of the 16th World Conference on Earthquake Engineering, Paper No. 0350, 9-13 January Santiago, Chile.

Gulkan, P., and Sozen, M.A., 1974. Inelastic response of reinforced concrete structures to earthquake motions, ACI Journal 71(12), 604-610.

Hutchinson, T., Boulanger, R., Chai, Y., and Idriss, I, 2002. Inelastic Seismic Response of Extended Pile Shaft Supported Bridge Structure, Report PEER 2002/14, Pacific Earthquake Engineering Research Center (PEER), University of California, Berkeley, CA.

Kowalsky, M. J., Priestley, M. J. N., and MacRae, G. A., 1994a. Displacement-Based Design-A Methodology for Seismic Design Applied to Single Degree of Freedom Reinforced Concrete Structures, Report No. SSRP-94/16, University of California, San Diego.

Kowalsky, M. J., Priestley, M. J. N., and MacRae, G. A., 1994b. Displacement-based design of RC bridge columns. In Proceedings of the 2nd International Workshop on the Seismic Design of Bridges, 8-13 August, Queenstown, New Zealand.

MathWorks, 2014. MATLAB Release 2014a, Natick, MA.

McKenna, F., and Fenves, G., 2011. OpenSees software: Version 2.3.1, Pacific Earthquake Engineering Center, (PEER), University of California, Berkeley, http://www.opensees. berkeley.edu.

PEER (Pacific Earthquake Engineering Research Center), 2013. NGAWest-2 Ground Motion Database, University of California, Berkeley, CA, http://ngawest2.berkeley.edu.

Priestley, M. J. N., Sieble, F., and Calvi, G. M., 1996. Seismic Design and Retrofit of Bridges, John Wiley \& Sons, New York.

Shibata, A., and Sozen, M. A., 1976. Substitute-structure method for seismic design in R/C, Journal of the Structural Division 102(ST1), 1-17.

Somerville, P., Smith, N., Punyamurthula, S., and Sun, J., 1997. Development of Ground Motion Time Histories for Phase 2 of the FEMA/SAC Steel Project, Report No. SAC/BD-9/04, SAC Joint Venture, Sacramento, CA.

Sozen, M. A., 2003. The velocity of displacement. In Seismic Assessment and Rehabilitation of Existing Buildings, S. T. Wasti and G. Ozcebe, eds. NATO Science Series (Series IV: Earth and Environmental Sciences), Springer, Dordrecht, 11-28.

Takeda, T., Sozen, M. A., and Nielsen, N. N., 1970. Reinforced concrete response to simulated earthquakes. in Journal of the Structural Division, Proceedings of the American Society of Civil Engineers 96(ST12), 2557-2573.

(Received 9 March 2017; accepted 4 January 2018) 